\title{
Application of PROMETHEE-GAIA method for non-traditional machining processes selection
}

\author{
Prasad Karande ${ }^{a}$ and Shankar Chakraborty ${ }^{b *}$
}

${ }^{a}$ Mechanical Engineering Department, Government Polytechnic, Mumbai - 400 051, Maharashtra, India

${ }^{b}$ Department of Production Engineering, Jadavpur University, Kolkata - 700032, India

\begin{tabular}{l}
\hline A R T I C L E I N F O \\
\hline Article history: \\
Received April 17, 2012 \\
Accepted 11 June 2012 \\
Available online \\
June 12 2012 \\
\hline Keywords: \\
Non-traditional machining \\
process \\
PROMETHEE \\
GAIA plane \\
Rank
\end{tabular}
\begin{abstract}
A B S T R A C T
With ever increasing demand for manufactured products of hard alloys and metals with high surface finish and complex shape geometry, more interest is now being paid to non-traditional machining (NTM) processes, where energy in its direct form is used to remove material from workpiece surface. Compared to conventional machining processes, NTM processes possess almost unlimited capabilities and there is a strong believe that use of NTM processes would go on increasing in diverse range of applications. Presence of a large number of NTM processes along with complex characteristics and capabilities, and lack of experts in NTM process selection domain compel for development of a structured approach for NTM process selection for a given machining application. Past researchers have already attempted to solve NTM process selection problems using various complex mathematical approaches which often require a profound knowledge in mathematics/artificial intelligence from the part of process engineers. In this paper, four NTM process selection problems are solved using an integrated PROMETHEE (preference ranking organization method for enrichment evaluation) and GAIA (geometrical analysis for interactive aid) method which would act as a visual decision aid to the process engineers. The observed results are quite satisfactory and exactly match with the expected solutions.
\end{abstract}

\section{Introduction}

Non-traditional machining (NTM) methods are a group of processes that remove material from the workpiece surface by various techniques involving mechanical, thermal, electrical or chemical energy (or combinations of these energies), but do not use a sharp cutting tool as in the conventional machining processes. Developed since World War II in response to new and unusual machining requirements that could not be satisfied by the conventional machining processes, these NTM processes now become indispensable to machine newly developed hard-to-machine metals and nonmetals with high surface finish, minimum surface damage and complex part geometry (Pandey \& Shan, 2005). The conventional machining processes mostly remove material in the form of chips by applying forces on the work material with a wedge-shaped cutting tool that is harder than the work

\footnotetext{
* Corresponding author.

E-mail addresses: s_chakraborty00@yahoo.co.in (S. Chakraborty) 
material under the specific machining condition. Such forces induce plastic deformation within the workpiece leading to shear deformation along the shear plane and chip formation. Using conventional methods to machine hard metals and alloys means increased demand of time and energy and therefore increases in costs; in some cases, conventional machining may not be feasible. Conventional machining also costs in terms of tool wear and loss of quality in the product owing to induced residual stresses. But new exotic work materials as well as innovative geometric design of products/components have been putting lot of pressure on the capabilities of conventional machining processes to manufacture components with the desired tolerances economically. This has led to the development and establishment of NTM processes in the industry as efficient and economic alternatives to conventional ones. Although the NTM processes would probably never replace the conventional machining processes currently used in industry, the newer methods ensure an increasingly important role because of their steadily improving capabilities (Jain, 2005).

The NTM processes utilize four main forms of energy, i.e. mechanical, thermal, electrical and chemical energy. Erosion of work material by a high velocity stream of abrasives or fluid (or both) is the typical mechanical action. Thermal energy is usually applied to small portion of work surface, causing that portion to be removed by fusion and/or evaporation. Material is also removed from the workpiece surface using electrical sparks or discharges. Chemical etchants selectively remove materials from portions of the workpiece, while other portions are protected by a mask. Electrochemical energy is also sometimes used to remove material from the workpiece. Due to the presence of complex physical characteristics of various NTM processes along with a dearth of experts in this domain, it becomes quite difficult for a process engineer to select the most appropriate NTM process for a specific machining application. A particular NTM process found suitable under the given conditions may not be equally efficient under other conditions. Therefore, a careful selection of NTM process for a given machining problem is essential while considering the following important attributes:

a) physical and operational characteristics of the NTM processes,

b) capability of machining different shapes of work material,

c) applicability of different processes to various types of materials, and

d) economics of various NTM processes.

The earlier researchers have already employed various tools and techniques, like computer-aided decision-making method (Cogun, 1993, 1994), combined analytic hierarchy process (AHP) and technique for order performance by similarity to ideal solution (TOPSIS) method (Yurdakul \& Cogun, 2003; Chakladar \& Chakraborty, 2008), AHP method (Chakraborty \& Dey, 2006), management information system (Chakrabarti et al., 2007), quality function deployment-based expert system (Chakraborty \& Dey, 2007), web-based knowledge base system (Chandraseelan et al., 2008), digraph-based expert system (Chakladar et al., 2009), analytic network process (ANP) (Das \& Chakraborty, 2011), data envelopment analysis (DEA) (Sadhu \& Chakraborty, 2011) and multiobjective optimization using ratio analysis (MOORA) method (Chakraborty, 2011) for selecting the best NTM processes for varying machining applications. It is sometimes not possible for the adopted multi-criteria decision-making (MCDM) methods, like AHP, ANP, TOPSIS, DEA etc. to provide optimal solutions to the NTM process selection problems due to the involvement of the decision makers in pair-wise comparing the performance of different NTM processes with respect to the considered selection criteria. Again, those MCDM methods do not perform well when the NTM process selection problems have a large number of alternatives and criteria. On the other hand, the development of knowledge-base expert systems depends on the availability of the expertise of the concerned process engineers. The augmented rules in those expert systems are sometimes static and only suitable for a specific machining application. The users do not obtain any idea about how the 
best NTM process selection decision has been arrived at and what are the effects of various criteria on the optimal decision.

Although at present, numerous NTM processes are available to machine various complex shape geometries in different work materials, in this paper, ten NTM processes, i.e. ultrasonic machining (USM), water jet machining (WJM), abrasive jet machining (AJM), electrochemical machining (ECM), chemical machining (CHM), electric discharge machining (EDM), wire electric discharge machining (WEDM), electron beam machining (EBM), laser beam machining (LBM) and plasma arc machining (PAM) are taken into account which can machine diverse materials, like aluminium, steel, super alloys, titanium, refractories, plastics, ceramics and glass. These NTM processes can generate precision holes, standard holes (with slenderness ratio $\leq 20$ ), standard holes (with slenderness ratio $>$ 20), precision through cavities and standard through cavities. They can also perform double contouring, surface of revolution, shallow and deep through cutting operations on different work materials.

This paper applies an integrated PROMETHEE (preference ranking organization method for enrichment evaluation) and GAIA (geometrical analysis for interactive aid) method to help the process engineers in selecting the most appropriate NTM process for a given work material and shape feature combination. Four real time examples are solved using this combined approach and the results exactly match with those identified by the past researchers which prove the universal acceptability of this method as an efficient visual decision aid.

\section{PROMETHEE-GAIA method}

The PROMETHEE methods, including PROMETHEE I for partial ranking of the alternatives and PROMETHEE II for complete ranking of the alternatives, were developed by Brans (Brans \& Vincke, 1985; Brans et al. 1986; Brans \& Mareschal, 1994). Thereafter, several other versions of PROMETHEE method, like PROMETHEE III for ranking based on interval, PROMETHEE IV for complete or partial ranking of the alternatives with a continuous set of viable solutions, PROMETHEE V for problems with segmentation constraints, PROMETHEE VI for human brain representation, PROMETHEE GDSS for group decision-making and the visual interactive module GAIA for graphical representation were subsequently developed for solving more complex decisionmaking problems. In the area of decision-making, PROMETHEE methods have become quite popular because of their simpler mathematical properties and user friendliness (De Keyser \& Peeters, 1996; Behzadian et al., 2010). The PROMETHEE method starts with the following decision matrix:

$$
\left[\begin{array}{cccccc}
g_{l}\left(a_{1}\right) & g_{2}\left(a_{1}\right) & \ldots & g_{j}\left(a_{1}\right) & \ldots & g_{n}\left(a_{1}\right) \\
g_{l}\left(a_{2}\right) & g_{2}\left(a_{2}\right) & \ldots & g_{j}\left(a_{2}\right) & \ldots & g_{n}\left(a_{2}\right) \\
\ldots & \ldots & \ldots & \ldots & \ldots & \ldots \\
g_{l}\left(a_{i}\right) & g_{2}\left(a_{i}\right) & \ldots & g_{j}\left(a_{i}\right) & \ldots & g_{n}\left(a_{i}\right) \\
\ldots & \ldots & \ldots & \ldots & \ldots & \ldots \\
g_{l}\left(a_{m}\right) & g_{2}\left(a_{m}\right) & \ldots & g_{j}\left(a_{m}\right) & \ldots & g_{n}\left(a_{m}\right)
\end{array}\right]
$$

where $g_{j}\left(a_{i}\right)$ is the performance of $i^{\text {th }}$ alternative on $j^{\text {th }}$ criterion, $m$ is the number of alternatives and $n$ is the number of criteria. The preference structure of PROMETHEE method is based on pair-wise comparisons, where the deviation between the evaluations of two alternatives on a specific criterion is considered. Here larger deviation signifies larger preference. These preferences usually range between 0 and 1 . For each criterion, the following preference function can be developed

$P_{j}(a, b)=F_{j}\left[d_{j}(a, b)\right] \quad \forall a, b \in A$

where $d_{j}(a, b)=\left[\mathrm{g}_{j}(a)-\mathrm{g}_{j}(b)\right]$ and $0 \leq P_{j}(a, b) \leq 1$. 
For beneficial criteria (where higher values are desired), this function gives the preference of alternative ' $a$ ' over alternative ' $b$ ' for the observed deviations between their evaluations on $j^{\text {th }}$ criterion. The preference is set to 0 when the deviations are negative.

For non-beneficial criteria (where lower values are preferred), the preference function can be rewritten as follows:

$$
P_{j}(a, b)=F_{j}\left[-d_{j}(a, b)\right]
$$

There are six basic types of preference function, i.e. usual criterion, U-shape criterion, V-shape criterion, level shape criterion, V-shape with indifference criterion and Gaussian criterion, as available to the decision maker. In some of these preference functions, different threshold parameters ( $p, q$ or $s$ ) need to be specified by the decision maker which constrains their applications. Among these preference functions, usual criterion is observed to be the simplest one. For the application of PROMETHEE method, the evaluation/decision matrix $\mathrm{g}_{j}($.$) , the relative importance (weight) of j^{\text {th }}$ criterion $\left(w_{j}\right)$ and the generalized criterion, $\left\{\mathrm{g}_{j}(),. P_{j}(a, b)\right\}$ need to be defined. PROMETHEE I method is based on pair-wise comparisons where the aggregated preference indices are defined as follows:

$$
\left\{\begin{array}{l}
\pi(a, b)=\sum_{j=1}^{n} w_{j} P_{j}(a, b) \\
\pi(b, a)=\sum_{j=1}^{n} w_{j} P_{j}(b, a)
\end{array}\right.
$$

where $\pi(a, b)$ measures the degree with which ' $a$ ' is preferred to ' $b$ ' over all the criteria and $\pi(b, a)$ represents the preference of ' $b$ ' over ' $a$ '. In most of the decision-making problems, there are some criteria for which ' $a$ ' is better than ' $b$ ', and criteria for which ' $b$ ' is better than ' $a$ ', and thus, $\pi(a, b)$ and $\pi(b, a)$ are usually positive. When the values of $\pi(a, b)$ and $\pi(b, a)$ are computed for each pair of alternatives in the decision matrix, a complete outranking relation graph can be obtained. Here, each alternative ' $a$ ' faces exactly ( $m-1)$ number of other alternatives in the decision matrix. Now, the positive and the negative outranking flows can be defined as below:

Positive outranking flow, $\varphi^{+}(a)=\frac{1}{m-1} \sum_{x \in A} \pi(a, x)$

Negative outranking flow, $\varphi^{-}(a)=\frac{1}{m-1} \sum_{x \in A} \pi(x, a)$

The positive outranking flow denotes how an alternative ' $a$ ' outranks all the other alternatives. The higher the value of $\varphi^{+}(a)$, the better is the alternative. The negative outranking flow measures how an alternative ' $a$ ' is being outranked by all other alternatives. Lower value of $\varphi^{-}(a)$ directs towards better alternative. In PROMETHEE I method, the partial ranking of the alternatives is derived from the positive and negative outranking flows. Both the flows do not usually provide the same rankings. On the other hand, PROMETHEE II method provides a complete preorder of the alternatives while using a net flow, although there is a chance of losing some information on the preference relations. Here, there is a balance between the positive and negative outranking flows. The net outranking flow for each alternative is obtained from the following expression:

$\varphi(a)=\varphi^{+}(a)-\varphi^{-}(a)$

A higher value of $\varphi(a)$ signifies better alternative. Thus, the best alternative has always the highest $\varphi(a)$ value. From the positive and negative outranking flows, the net outranking flow value can be reformulated, as follows: 
$\varphi(a)=\varphi^{+}(a)-\varphi^{-}(a)=\frac{1}{m-1} \sum_{j=1}^{n} \sum_{x \in A}\left[P_{j}(a, x)-P_{j}(x, a)\right] w_{j}$

Thus,

$\varphi(a)=\sum_{j=1}^{n} w_{j} \varphi_{j}(a)$

if $\varphi_{j}(a)=\frac{1}{m-1} \sum_{x \in A}\left[P_{j}(a, x)-P_{j}(x, a)\right]$

where $\varphi_{j}(a)$ is the single criterion net flow obtained for $j^{\text {th }}$ criterion. It is observed that the global net flow of an alternative is the scalar product of vector of the criteria weights and profile vector of that alternative. This property is primarily used for developing the GAIA plane. Now, the matrix $M_{(m \times n)}$ is defined based on the single criterion net flows of all the alternatives.

$M=\left[\begin{array}{cccccc}\varphi_{l}\left(a_{1}\right) & \varphi_{2}\left(a_{1}\right) & \ldots & \varphi_{j}\left(a_{1}\right) & \ldots & \varphi_{n}\left(a_{1}\right) \\ \varphi_{l}\left(a_{2}\right) & \varphi_{2}\left(a_{2}\right) & \ldots & \varphi_{j}\left(a_{2}\right) & \ldots & \varphi_{n}\left(a_{2}\right) \\ \ldots & \ldots & \ldots & \ldots & \ldots & \ldots \\ \varphi_{l}\left(a_{i}\right) & \varphi_{2}\left(a_{i}\right) & \ldots & \varphi_{j}\left(a_{i}\right) & \ldots & \varphi_{n}\left(a_{i}\right) \\ \ldots & \ldots & \ldots & \ldots & \ldots & \ldots \\ \varphi_{l}\left(a_{m}\right) & \varphi_{2}\left(a_{m}\right) & \ldots & \varphi_{j}\left(a_{m}\right) & \ldots & \varphi_{n}\left(a_{m}\right)\end{array}\right]$

Matrix $M$ is more useful than the decision/evaluation matrix because the degrees of preference provided by the generalized criteria are considered in $M$. Moreover, in the decision matrix, $\mathrm{g}_{j}\left(a_{i}\right)$ values are expressed on their own scale, while in matrix $M, \varphi_{j}\left(a_{i}\right)$ values are dimensionless. In addition, matrix $M$ does not depend on criteria weights. The set of $m$ alternatives can be represented as a cluster of $m$ points in a $n$-dimensional space. When the number of criteria becomes larger than two, it is difficult to obtain a clear view of the relative position of the alternatives with regard to the criteria. The GAIA plane is developed by projecting these points on a plane such that very little information are lost. In this plane, alternatives $\left(a_{1}, a_{2}, \ldots, a_{m}\right)$ are represented by points and the criteria $\left(c_{1}, c_{2}, \ldots, c_{n}\right)$ are denoted by axes. From Eqn. (9), it can be said that the net flow $a_{i}$ is the projection of the vector of its single criterion net flows on $w$. Consequently, the relative positions of the projections of all the alternatives on $w$ provides the PROMETHEE ranking of the alternatives. Clearly, the vector $w$ plays an important role. It is represented in GAIA plane by the projection of the unit vector of the weights. This projection is referred to as the PROMETHEE decision axis $(\pi)$. This axis directs towards the compromise solution resulting from the weights allocated to the criteria. If a particular criterion has the maximum relative importance (weight), the $\pi$ axis will coincide with the axis of that criterion in GAIA plane. When the weights are distributed among all the criteria, the $\pi$ axis appears as a weighted resultant of all the criteria axes.

A long $\pi$ axis signifies a strong decision power, inviting the decision maker to select alternatives as far as possible on its direction. On the other hand, a short $\pi$ axis has no strong decision power, the criteria are strongly conflicting and the selection of a good compromise solution is a hard problem. In GAIA plane, criteria expressing similar preferences on the evaluation data are oriented in the same direction, and the conflicting criteria are pointing in the opposite directions. When the weights are modified, the positions of the alternatives and those of the criteria remain unchanged in GAIA plane. The weight vector appears as a decision stick that the decision maker can move according to the preference in favor of a particular criterion. When a sensitivity analysis is performed by modifying the weights, the PROMETHEE decision stick $(w)$ and the $\pi$ axis are moving in such a way that the consequences for decision-making are easily observed in GAIA plane. 


\section{Illustrative examples}

To justify the applicability, usefulness and accuracy of PROMETHEE-GAIA method in selecting the most suitable NTM process for a given machining application, the following four examples are analyzed and solved. For all these cases, the derived results are compared with those observed by the past researchers which prove the suitability of this integrated method as an effective user-interactive visual decision-making tool for NTM process selection.

\subsection{Example 1}

In this example, pockets having dimensions length $16.5 \mathrm{~mm}$, width $8.9 \mathrm{~mm}$ and depth $2.3 \mathrm{~mm}$ were generated on 4140 die steel within a tolerance of $0.13 \mathrm{~mm}$. Yurdakul and Cogun (2003) eliminated WJM, ECG, ECH, WEDM, EBM, LBM and PAC processes (on the basis of shape applications), and also USM and CHM (on the basis of process capabilities) processes, and identified the pertinent attributes as surface finish (SF), surface damage (SD), corner radii (CR), taper (T), material removal rate (MRR), work material (WM) and cost (C), affecting the NTM process selection decision. Yurdakul and Cogun (2003) developed the decision matrix of Table 1 where only three NTM processes (AJM, ECM and EDM) were considered as feasible alternatives to generate pockets of the desired dimensions on steel. Using AHP method, the criteria weights were determined as $\mathrm{w}_{\mathrm{SF}}=0.27$, $\mathrm{w}_{\mathrm{SD}}=0.05, \mathrm{w}_{\mathrm{SF}}=0.27, \mathrm{w}_{\mathrm{CR}}=0.05, \mathrm{w}_{\mathrm{T}}=0.05, \mathrm{w}_{\mathrm{MRR}}=0.27, \mathrm{w}_{\mathrm{WM}}=0.05$ and $\mathrm{w}_{\mathrm{C}}=0.05$, which are subsequently used here in the PROMETHEE-GAIA method-based analysis. In this example, SF, SD, $\mathrm{CR}, \mathrm{T}$ and $\mathrm{C}$ are non-beneficial attributes, and MRR and $\mathrm{WM}$ are beneficial attributes. The initial input window of PROMETHEE-GAIA software is shown in Figure 1 where the user can easily set the number of alternatives, number of criteria, number of scenarios for group decision-making problems, type of each criterion (beneficial or non-beneficial), weights for the criteria and unit for each criterion. The PROMETHEE-GAIA software can be easily downloaded from www.prometheegaia.net/software.html website. Among the six possible preference functions for PROMETHEE method, the simplest one (usual criterion) is chosen here. If the user selects the other preference functions, the corresponding threshold values ( $\mathrm{p}, \mathrm{q}$ or $\mathrm{s}$ ) need to be specified by the decision maker in the input window.

Table 1

Decision matrix for example 1 (Yurdakul and Cogun, 2003)

\begin{tabular}{llllllll}
\hline $\begin{array}{l}\text { NTM } \\
\text { processe }\end{array}$ & $\begin{array}{l}\text { Surface } \\
\text { finish }\end{array}$ & $\begin{array}{l}\text { Surface } \\
\text { damage }\end{array}$ & $\begin{array}{l}\text { Corner } \\
\text { radii }\end{array}$ & Taper & MRR & $\begin{array}{l}\text { Work } \\
\text { material }\end{array}$ & Cost \\
\hline AJM & 0.6 & 2.5 & 0.3 & 0.005 & 50 & 2 & 4 \\
ECM & 1 & 0 & 0.2 & 0.001 & 2000 & 3 & 4 \\
EDM & 2 & 20 & 0.4 & 0.001 & 800 & 3 & 7 \\
\hline
\end{tabular}

When this NTM process selection problem of pocketing operation on steel is solved using PROMETHEE-GAIA software, ECM emerges out as the most suitable NTM process, as displayed in Figure 2. EDM process is the worst choice and the capability of AJM process falls in between ECM and EDM processes. The developed GAIA plane is shown in Figure 3 where the decision axis $(\pi)$ points towards ECM process, indicating its suitability to generate pockets of the required dimensions on steel. It is noted that material removal rate $\left(\mathrm{C}_{5}\right)$ and work material $\left(\mathrm{C}_{6}\right)$, and surface finish $\left(\mathrm{C}_{1}\right)$, surface damage $\left(\mathrm{C}_{2}\right)$, corner radii $\left(\mathrm{C}_{3}\right)$, taper $\left(\mathrm{C}_{4}\right)$ and cost $\left(\mathrm{C}_{7}\right)$ are the conflicting criteria as they are oriented totally in opposite directions. In GAIA plane, criteria $\mathrm{C}_{2}, \mathrm{C}_{3}$ and $\mathrm{C}_{4}$ are superimposed on each other, suggesting that these three criteria have the same impact on this NTM process selection problem. It means that these three criteria are almost correlated. Criteria $\mathrm{C}_{5}$ and $\mathrm{C}_{7}$, and criteria $\mathrm{C}_{6}$ and $\mathrm{C}_{7}$ are not related to each other with respect to preferences as they are represented by orthogonal axes. It is also observed that this NTM process selection problem has a solution accuracy (reliability) of $100 \%$. Figure 4 exhibits the walking weight diagram for this NTM process selection problem 
where the process engineer can easily modify the criteria weights to visualize the effects of those changing weights on the ranking of the alternative NTM processes. It basically acts as a sensitivity analysis tool. Using a combined AHP and TOPSIS method, Yurdakul and Cogun (2003) also recommended ECM as the best NTM process for this machining application.

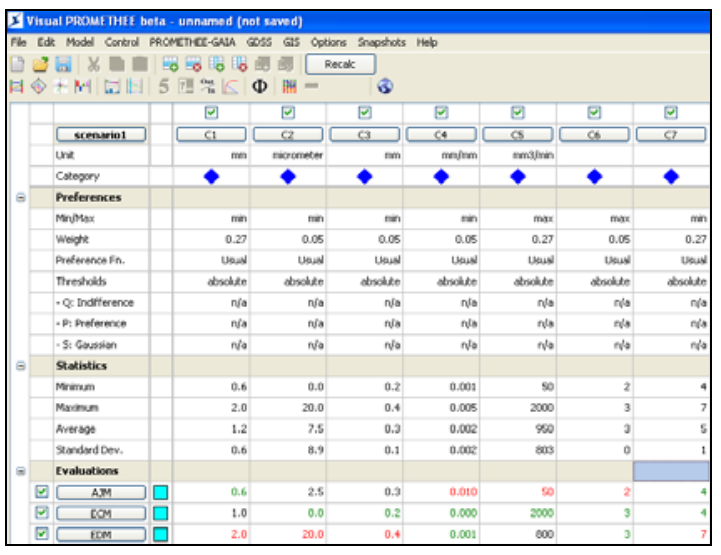

Fig. 1. Input window for example 1

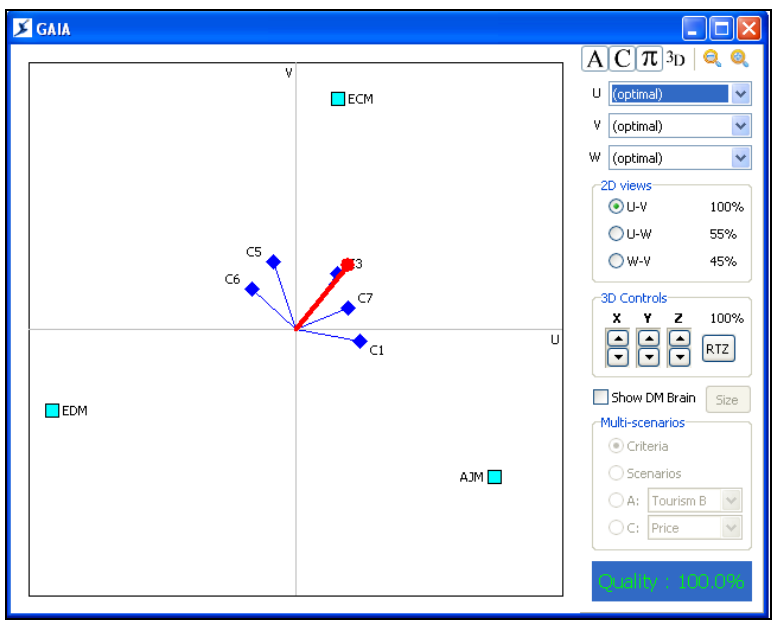

Fig. 3. GAIA plane for example 1

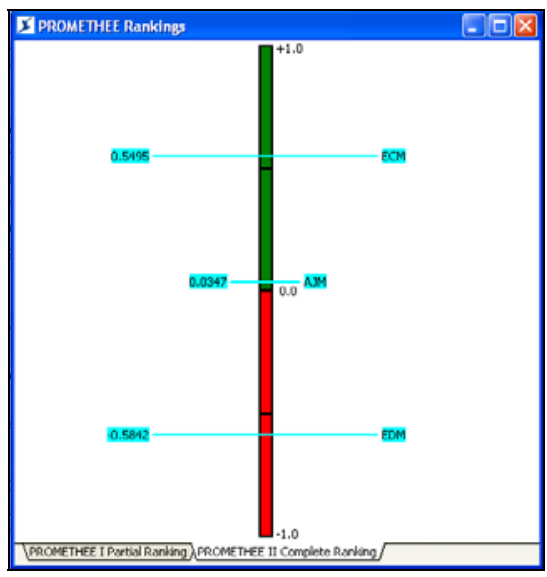

Fig. 2. PROMETHEE II complete ranking for example 1

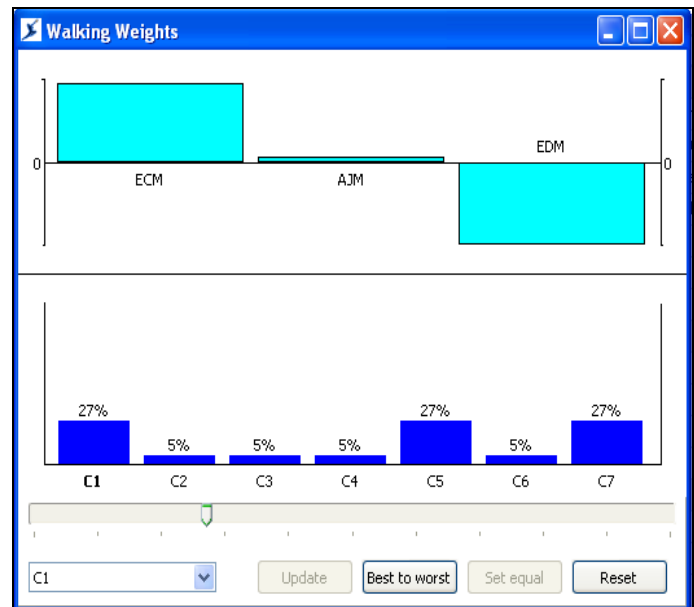

Fig. 4. Walking weights for example 1

\subsection{Example 2}

Yurdakul and Cogun (2003) considered this example where cylindrical through hole drilling (930 holes of $0.64 \mathrm{~mm}$ diameter and slenderness ratio of 5.7) was performed on ceramic (non-conductive) material. ECM, ECG, ECH, EDM, WEDM and PAC processes were initially eliminated from further consideration on the basis of work material, and WJM process was discarded based on shape application. The feasible alternatives to be ranked were AJM, USM, CHM, EBM and LBM processes for which the corresponding decision matrix was developed, as shown in Table 2. Among the seven considered criteria, tolerance (TL), surface finish (SF), surface damage (SD), taper (T) and cost (C) are non-beneficial in nature, whereas, material removal rate (MRR) and work material (WM) are beneficial in nature. The criteria weights for those criteria were determined as $\mathrm{w}_{\mathrm{TL}}=0.32, \mathrm{w}_{\mathrm{SF}}=0.19$, $\mathrm{w}_{\mathrm{SD}}=0.04, \mathrm{w}_{\mathrm{T}}=0.04, \mathrm{w}_{\mathrm{MRR}}=0.19, \mathrm{w}_{\mathrm{WM}}=0.11$ and $\mathrm{w}_{\mathrm{C}}=0.11$. Yurdakul and Cogun (2003) observed that USM was the most suitable NTM process for generating through holes on ceramic material. Figure 5 shows the ranking of the considered NTM processes as obtained using 
PROMETHEE II method for this work material and shape feature combination, and it is quite evident that USM is the best NTM process. On the other hand, the performance of CHM process is not so much satisfactory. In the GAIA plane, as exhibited in Figure 6, the decision axis clearly points towards USM process, proving its suitability to machine through holes on ceramic material. For this machining application, the performances of EBM and LBM processes are almost similar. The position of CHM process in the GAIA plane is rather ambiguous which may be the reason for its attaining the last rank in this NTM process selection problem. In the GAIA plane, tolerance $\left(\mathrm{C}_{1}\right)$ and cost $\left(\mathrm{C}_{7}\right)$, tolerance $\left(\mathrm{C}_{1}\right)$ and MRR $\left(\mathrm{C}_{5}\right)$, surface damage $\left(\mathrm{C}_{3}\right)$ and taper $\left(\mathrm{C}_{4}\right)$, and MRR $\left(\mathrm{C}_{5}\right)$ and work material $\left(\mathrm{C}_{6}\right)$ are not related with each other as they lie along the orthogonal axes. It is observed from Figure 6 that EBM and LBM processes are better with respect to $\operatorname{cost}\left(\mathrm{C}_{7}\right)$ criterion, and AJM process is better with respect to surface damage $\left(\mathrm{C}_{3}\right)$ criterion. On the other hand, USM process supersedes all other considered NTM processes with respect to the remaining five criteria. It is also found that this NTM process selection problem for generating through holes on ceramic material has a good solution accuracy of $85.2 \%$ and a long decision axis in the GAIA plane assures an almost accurate solution.

Table 2

Decision matrix for example 2 (Yurdakul \& Cogun, 2003)

\begin{tabular}{llllllll}
\hline $\begin{array}{l}\text { NTM } \\
\text { processes }\end{array}$ & Tolerance & $\begin{array}{l}\text { Surface } \\
\text { finish }\end{array}$ & $\begin{array}{l}\text { Surface } \\
\text { damage }\end{array}$ & Taper & MRR & $\begin{array}{l}\text { Work } \\
\text { material }\end{array}$ & Cost \\
\hline AJM & 0.05 & 0.6 & 2.5 & 0.005 & 50 & 3 & 4 \\
USM & 0.013 & 0.5 & 25 & 0.005 & 500 & 3 & 5 \\
CHM & 0.03 & 2 & 5 & 0.3 & 40 & 1 & 2 \\
EBM & 0.02 & 3 & 100 & 0.02 & 2 & 3 & 1 \\
LBM & 0.02 & 1 & 100 & 0.05 & 2 & 3 & 1 \\
\hline
\end{tabular}

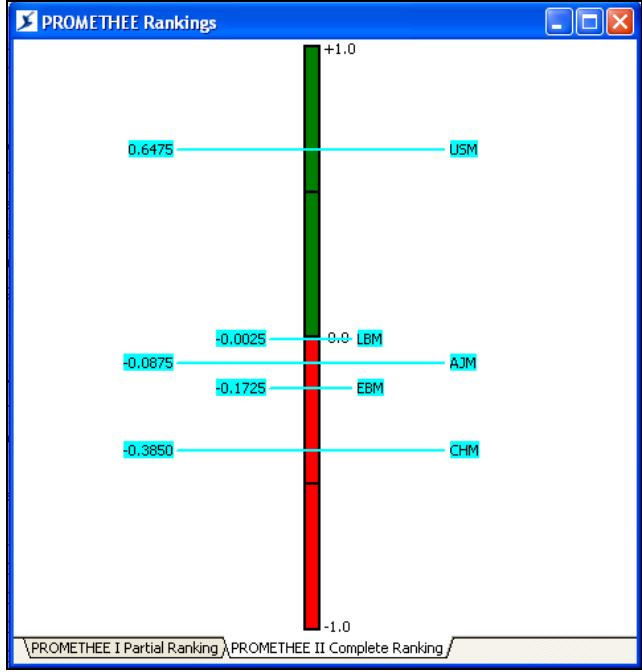

Fig. 5. PROMETHEE II complete ranking for example 2

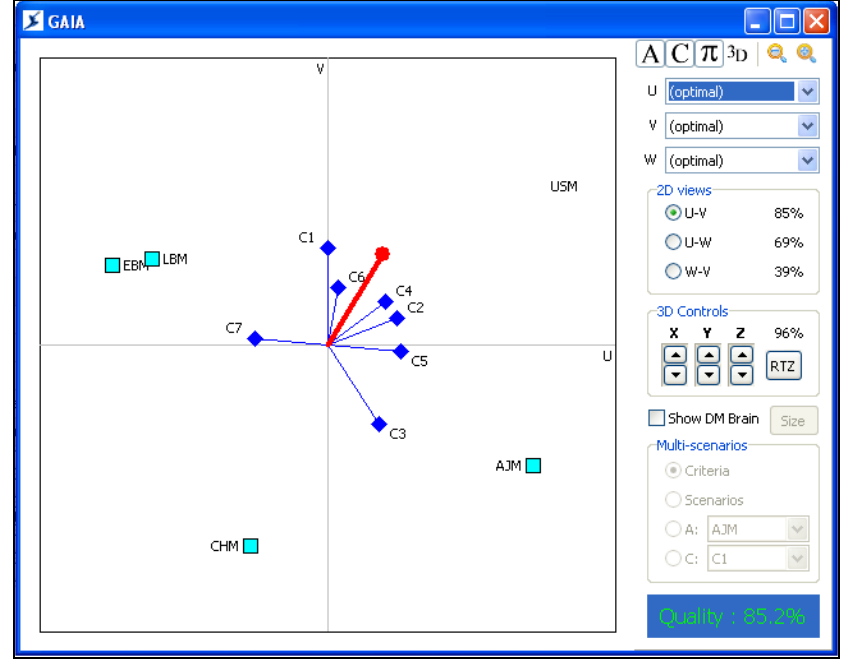

Fig. 6. GAIA plane for example 2

\subsection{Example 3}

Chakladar and Chakraborty (2008) considered a NTM process selection problem where precision holes were generated on Duralumin (aluminum alloy). For that problem, the following decision matrix of Table 3 was developed, consisting of nine alternative NTM processes and ten selection criteria. Among these ten criteria, material removal rate (MRR), efficiency (E), safety (S), work material $(\mathrm{M})$, and shape feature $(\mathrm{F})$ are beneficial attributes, and on the other hand, tolerance and surface finish (TSF), power requirement (PR), cost (C), tooling and fixtures (TF) and tool 
consumption (TC) are non-beneficial attributes. Using AHP method, the criteria weights were determined as $\mathrm{w}_{\mathrm{TSF}}=0.0783, \mathrm{w}_{\mathrm{PR}}=0.0611, \mathrm{w}_{\mathrm{MRR}}=0.1535, \mathrm{w}_{\mathrm{C}}=0.1073, \mathrm{w}_{\mathrm{E}}=0.0383, \mathrm{w}_{\mathrm{TF}}=$ $0.0271, \mathrm{w}_{\mathrm{TC}}=0.0195 . \mathrm{w}_{\mathrm{S}}=0.0146, \mathrm{w}_{\mathrm{M}}=0.2766$ and $\mathrm{w}_{\mathrm{F}}=0.2237$, which are used for the PROMETHEE-GAIA method-based analysis. While applying a combined AHP-TOPSIS method, Chakladar and Chakraborty (2008) obtained a ranking of NTM processes as EDM-ECM-WEDMCHM-USM-EBM-LBM-WJM-AJM in descending order of preference. When the same problem is solved using PROMETHEE-GAIA method, EDM is observed to be the most appropriate NTM process for this machining application, as shown in Figure 7. WEDM process has the second preference and AJM is the least favored NTM process. Some interesting observations can be investigated from the developed GAIA, as exhibited in Figure 8. The direction of the decision axis confirms the superiority of EDM process for machining of precision holes on Duralumin alloy. The performances of EDM and WEDM processes, and those of AJM and WJM processes are almost similar for this machining application. The superimposition of two criteria, $\operatorname{MRR}\left(\mathrm{C}_{3}\right)$ and work material $\left(\mathrm{C}_{9}\right)$ on each other indicates that they have the same effect on this NTM process selection decision. The importance of tolerance and surface finish $\left(\mathrm{C}_{1}\right)$, cost $\left(\mathrm{C}_{4}\right)$ and efficiency $\left(\mathrm{C}_{5}\right)$ are almost similar as they almost lie in the same cluster of the GAIA plane. A short decision axis suggests that for this NTM process selection problem, all the considered criteria are highly conflicting and finding out the best NTM process for this machining application is really a hard problem which is also verified by a poor solution accuracy of $65.7 \%$. Emergence of two NTM processes, i.e. EDM and WEDM, as the optimal solutions also confirms the complexity of this decision-making problem.

Table 3

Decision matrix for example 3 (Chakladar \& Chakraborty, 2008)

\begin{tabular}{lllllllllll}
\hline $\begin{array}{l}\text { NTM } \\
\text { processes }\end{array}$ & TSF & PR & MRR & C & E & TF & TC & S & M & F \\
\hline USM & 1.0 & 10.00 & 500.0 & 2 & 4 & 2 & 3 & 1 & 4 & 1 \\
WJM & 2.5 & 0.22 & 0.8 & 1 & 4 & 2 & 2 & 3 & 3 & 1 \\
AJM & 2.5 & 0.24 & 0.5 & 1 & 4 & 2 & 2 & 3 & 3 & 1 \\
ECM & 3.0 & 100.00 & 400.0 & 5 & 2 & 3 & 1 & 3 & 5 & 4 \\
CHM & 3.0 & 0.40 & 15.0 & 3 & 3 & 2 & 1 & 3 & 5 & 4 \\
EDM & 3.5 & 2.70 & 800.0 & 3 & 4 & 4 & 4 & 3 & 4 & 5 \\
WEDM & 3.5 & 2.50 & 600.0 & 3 & 4 & 4 & 4 & 3 & 4 & 5 \\
EBM & 2.5 & 0.20 & 1.6 & 4 & 5 & 2 & 1 & 3 & 4 & 1 \\
LBM & 2.0 & 1.40 & 0.1 & 3 & 5 & 2 & 1 & 1 & 4 & 1 \\
\hline
\end{tabular}

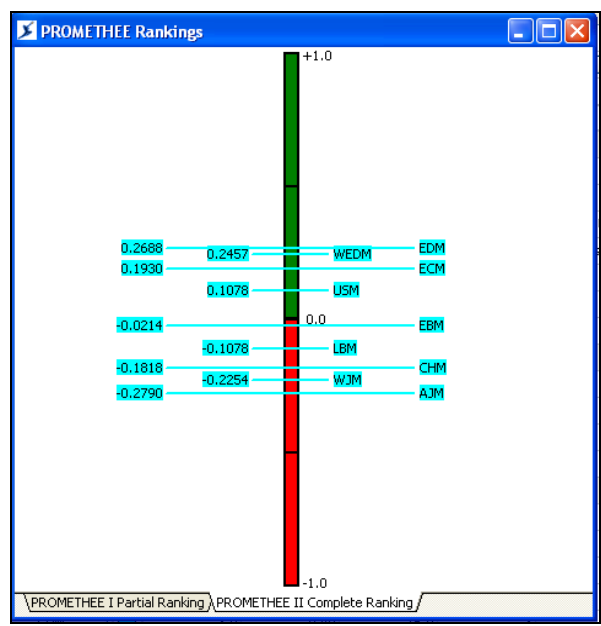

Fig.7. PROMETHEE II complete ranking for example 3

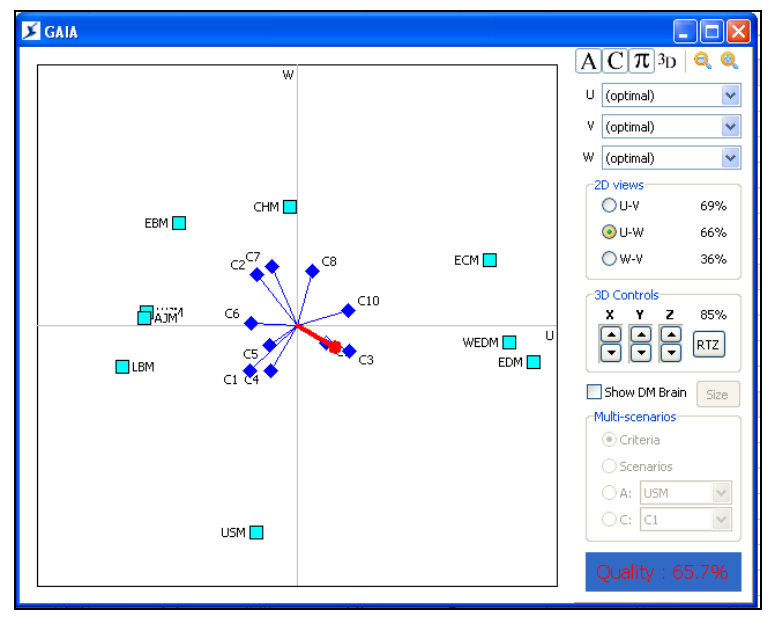

Fig. 8. GAIA plane for example 3 


\subsection{Example 4}

Chakladar et al. (2009) took this example of deep through cutting operation on titanium and solved it using a graph theory and matrix approach-based expert system. Six most important attributes, like tolerance and surface finish (TSF), material removal rate (MRR), power requirement (PR), cost (C), shape feature (F) and work material type (M) were considered, and it was observed that PAM was the most appropriate NTM process. EBM and AJM processes could also generate deep through cut on titanium, but having lower priorities than PAM process. The decision matrix for this machining application problem is exhibited in Table 4. The criteria weights were calculated as $\mathrm{w}_{\mathrm{TSF}}=0.03$, $\mathrm{w}_{\mathrm{MRR}}=0.36, \mathrm{w}_{\mathrm{PR}}=0.03, \mathrm{w}_{\mathrm{C}}=0.04, \mathrm{w}_{\mathrm{F}}=0.13$ and $\mathrm{w}_{\mathrm{M}}=0.40$. Among these six criteria, MRR, $\mathrm{F}$ and $\mathrm{M}$ are beneficial in nature, whereas, TSF, PR and $\mathrm{C}$ are non-beneficial criteria. When this problem is solved employing PROMETHEE-GAIA method, a complete ranking of the feasible NTM processes to perform deep through cutting operation on titanium is obtained, as shown in Figure 9. Out of all the eight considered NTM processes, PAM is found to be the best process, followed by ECM process. From Figure 9, it is also observed that LBM process is not at all suitable for this machining application. The corresponding GAIA plane is also developed for this problem, as displayed in Figure 10. As the long decision axis is directed towards PAM process, it can be accepted as the best NTM process. The performance of EDM process is also quite comparable to PAM process. These two NTM processes are better with respect to material removal rate $\left(\mathrm{C}_{2}\right)$ and work material type $\left(\mathrm{C}_{6}\right)$ criteria. AJM, USM and CHM processes are superior with respect to power requirement $\left(\mathrm{C}_{3}\right)$ criterion. Likewise, LBM and EBM processes would give better tolerance and surface finish, and ECM process has the capability to machine varying shape features on a given work material. Material removal rate $\left(\mathrm{C}_{2}\right)$ and cost $\left(\mathrm{C}_{4}\right)$, and shape feature $\left(\mathrm{C}_{5}\right)$ and work material type $\left(\mathrm{C}_{6}\right)$ are independent to each other as they are oriented in orthogonal axes. This problem has a good solution accuracy of $75.3 \%$.

\section{Table 4}

Decision matrix for example 4 (Chakladar et al., 2009)

\begin{tabular}{lllllll}
\hline NTM processes & TSF & MRR & PR & C & F & M \\
\hline AJM & 2.5 & 0.8 & 0.22 & 1 & 1 & 4 \\
USM & 1.0 & 300 & 2.4 & 2 & 1 & 4 \\
CHM & 3.0 & 15 & 0.4 & 3 & 1 & 4 \\
EBM & 2.5 & 1.6 & 0.2 & 4 & 4 & 4 \\
LBM & 2.0 & 0.1 & 1.4 & 3 & 4 & 4 \\
ECM & 3.0 & 1500 & 100 & 5 & 5 & 4 \\
EDM & 3.5 & 800 & 2.7 & 3 & 1 & 5 \\
PAM & 5.0 & 75000 & 50 & 1 & 5 & 4 \\
\hline
\end{tabular}

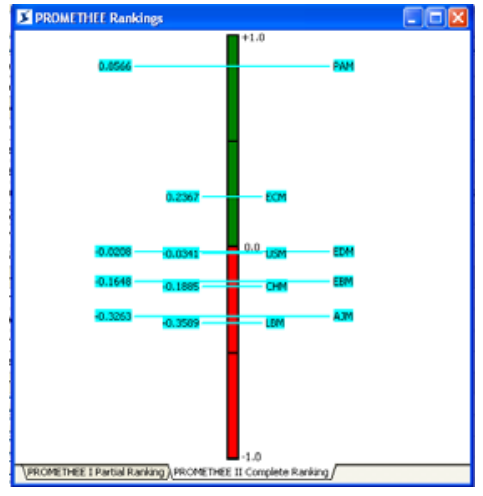

Fig. 9. PROMETHEE II complete ranking for example 4

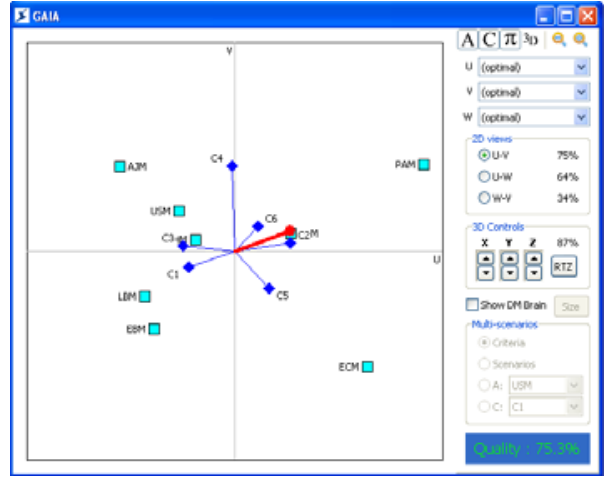

Fig. 10. GAIA plane for example 4 


\section{Conclusions}

Due to the presence of various physicochemical and physicothermal phenomena in NTM processes, and lack of enough expertise in this field, it becomes quite difficult for the process engineers to select the most appropriate NTM process to be applied for generation of a specific shape feature on a given work material. A good amount of mathematical models and knowledge-base expert systems have already been developed to assist the process engineers in selecting the best NTM process. But all these approaches require extensive knowledge in mathematics and computer science from the part of the process engineers. This paper provides the application of a PROMETHEE-GAIA method-based graphical tool in guiding the process engineers in arriving at the best NTM process selection decision. This combined methodology is quite simple, easy to understand and releases the process engineers from performing detailed mathematical computations. The walking weights diagram acts as a sensitivity analysis tool to show the effects of criteria weights on the final NTM process selection decision. It can also be successfully applied for other complex decision-making situations as being encountered in the present day manufacturing environment.

\section{References}

Behzadian, M., Kazemzadeh, R.B., Albadvi, A., \& Aghdasi, M. (2010). PROMETHEE: A comprehensive literature review on methodologies and applications. European Journal of Operational Research, 200, 198-215.

Brans, J.P., \& Vincke, P. (1985). A preference ranking organisation method: The PROMETHEE method for MCDM. Management Science, 31, 647-56.

Brans, J.P., Vincke, P., \& Mareschal, B. (1986). How to select and how to rank projects: The PROMETHEE method. European Journal of Operational Research, 24, 228-38.

Brans, J.P., \& Mareschal, B. (1994). The Promcalc and Gaia decision-support system for multicriteria decision aid. Decision Support Systems, 12, 297-310.

Chakladar, N.D., \& Chakraborty, S. (2008). A combined TOPSIS-AHP-method-based approach for non-traditional machining processes selection. Proc. IMechE Part B: Journal of Engineering Manufacture, 222, 1613-1623.

Chakladar, N.D., Das, R., \& Chakraborty, S. (2009). A digraph-based expert system for nontraditional machining processes selection. International Journal of Advanced Manufacturing Technology, 43, 226-237.

Chakraborty, S., \& Dey, S. (2006). Design of an analytic-hierarchy-process-based expert system for non-traditional machining process selection. International Journal of Advanced Manufacturing Technology, 31, 490-500.

Chakrabarti, S., Mitra, S., \& Bhattacharyya, B. (2007). Development of a management information system as knowledge base model for machining process characterization. International Journal of Advanced Manufacturing Technology, 34, 1088-1097.

Chakraborty, S., \& Dey, S. (2007). QFD-based expert system for non-traditional machining processes selection. Expert Systems with Applications, 32, 1208-1217.

Chakraborty, S. (2011). Applications of the MOORA method for decision making in manufacturing environment, International Journal of Advanced Manufacturing Technology, 54, 1155-1166.

Chandraseelan, E.R., Jehadeesan, R., \& Raajenthiren, M. (2008). Web-based knowledge base system for selection of non-traditional machining processes. Malaysian Journal of Computer Science, 21, 45-56.

Cogun, C. (1993). Computer-aided system for selection of nontraditional machining operations. Computers in Industry, 22, 169-179.

Cogun, C. (1994). Computer-aided preliminary selection of nontraditional machining processes. International Journal of Machine Tools \& Manufacturer, 34, 315-326.

Das, S., \& Chakraborty, S. (2011). Selection of non-traditional machining processes using analytic network process. Journal of Manufacturing Systems, 30, 41-53. 
De Keyser W., \& Peeters, P. (1996). A note on the use of PROMETHEE multicriteria methods. European Journal of Operational Research, 89, 457-461.

Jain, V.K. (2005). Advanced machining processes. New Delhi: Allied Publishers Pvt. Limited.

Pandey, P.C., \& Shan, H.S. (2005). Modern machining processes. New Delhi: Tata MacGraw-Hill Publishing Company Limited.

Yurdakul, M., \& Cogun, C. (2003). Development of a multi-attribute selection procedure for nontraditional machining processes. Proc. IMechE Part B: Journal of Engineering Engineering Manufacture, 217, 993-1009. 